\title{
Assessment of flood loss model transferability considering changes in precaution of flood-affected residents in Germany
}

\author{
Sarah Kienzler ${ }^{1, a}$, Heidi Kreibich ${ }^{2}$, Meike Müller ${ }^{3}$, Ina Pech ${ }^{1}$ and Annegret H. Thieken ${ }^{1}$ \\ ${ }^{1}$ University of Potsdam, Institute of Earth and Environmental Science, Karl-Liebknecht-Strasse 24-25, 14476 Potsdam-Golm, Germany \\ ${ }^{2}$ GFZ German Research Centre for Geosciences, Section 5.4 Hydrology, Telegrafenberg, 14473 Potsdam, Germany \\ ${ }^{3}$ Deutsche Rückversicherung AG, Hansaallee 177, 40549 Düsseldorf, Germany
}

\begin{abstract}
Common models that are used for flood loss assessments today rarely include multiple loss influencing factors, e.g. private precautionary measures, which is increasingly gaining attention in the course of the changes towards an integrated flood risk management. Furthermore, these models are often transferred to other flood events or regions without knowing to what extent this results in reliable estimates. Since data on explanatory variables and losses are often missing, model validation is scarcely performed. The aim of this study was therefore to investigate whether the multifactorial flood loss model FLEMO can be transferred in time and space, using the examples of the August 2002 and May/June 2013 flood events in Germany, with particular consideration of changes in property-level mitigation measures and loss reduction effects for residential buildings. The study revealed that the spatio-temporal transferability of flood loss models remains highly uncertain, since the models could only partially reproduce changes in property-level mitigation measures. This indicates that flood loss influencing processes and factors are still not yet sufficiently understood and represented in models due to complex interrelations and different flood and site specific characteristics. More research on changes in loss explanatory parameters and standardised data collection is needed to enhance the understanding of damage processes and to improve flood loss model validation.
\end{abstract}

\section{Introduction}

In Germany, an increasing trend of flood losses can be seen [1-3]. In the last 25 years, almost all major river catchments were at least once affected by floods, each of them causing losses running into EUR 100 million [4-5]. From these events particularly the flood in August 2002 along the rivers Elbe and Danube stands out, where 21 people were killed and a total loss of EUR 11.6 billion occurred (as at July 2005 [6]). Despite a hydrologically similar flood event in May/June 2013, this has been the most expensive natural disaster in Germany [5]. In this context, reliable models for estimating potentials flood losses are of great importance. They are used for loss predictions of future flood events, cost-benefit analyses regarding flood protection plans, vulnerability assessments, land-use planning, risk analyses and mapping as well as calculations of reconstruction aid and settling claims by the federal government and (re)insurance companies [7-8]. These models are often based on susceptibility functions, which predominantly relate the hazard parameter water depth to corresponding direct economic losses of different elements at risk, for example, residential buildings [8-10]. These depthdamage functions have been accepted internationally as a standard approach for estimating flood losses for a long time, but recent studies confirm that flood damage to

\footnotetext{
a Corresponding author: kienzler@uni-potsdam.de
}

residential buildings is controlled by further factors that either increase (impact parameters, e.g. flood duration, contamination of the flood water) or decrease (resistance parameters, e.g. building characteristics, early warning) losses. Hence, an increasing number of extended flood loss models have been developed. An overview of existing models and model comparisons can be found e.g. in $[8,10-16]$. In this context, studies of [16-19] confirm that multifactorial models can estimate flood losses more reliably than traditional depth-damage functions.

One influencing parameter that is increasingly gaining attention in flood risk assessment is private precaution. In the course of the changes towards an integrated flood risk management, which is not only based on technical flood protection but also considers non-structural measures to minimize adverse effects of flooding, the responsibility of flood-prone residents to contribute to flood loss mitigation has been greatly strengthened. Since 2005, private precaution is even legally consolidated in Germany. According to $\S 5$ section 2 of the Federal Water Resources Act, any person who may be affected by flooding is obligated to take appropriate precautionary measures within the bounds of their possible and reasonable resources to reduce flood impacts and to mitigate damage [20]. The positive loss reducing effect of private precautionary measures, especially of propertylevel mitigation measures, has been confirmed by an 
increasing number of studies, either by risk assessment modelling (e.g. [21-24]), expert judgement (e.g. [25-28]) or empirical studies (e.g. [29-32]). An overview of the loss reduction potential of specific measures can be found in [4]. For example, [33] compared the precautionary behaviour of private households before the Rhine floods in 1993 and 1995 and confirmed that initiated improvements in property-level mitigation measures after the flood in 1993 approximately halved the contents and buildings losses of the flood in 1995. [29] and [30] evaluated survey data of flood-affected households along the river Elbe and showed that in particular the implementation of property-level mitigation measures can be very effective, not only in areas with frequent small floods, but also for extreme flood events as in August 2002. For example, measures like flood-adapted building use and interior equipment as well as the installation of the heating system on higher floors reduced the average building loss by $46 \%, 53 \%$ and $36 \%$, respectively. The cost effectiveness of such measures was discussed in [34-35]. Against this background it can be assumed that an increase in implemented property-level mitigation measures might decrease building losses of future flood events, as demonstrated e.g. by [36].

Although the potential of property-level mitigation measures to reduce flood losses is often mentioned and demanded in the concepts of flood risk management, it is rarely included in flood loss modelling. One of few exceptions is the multifactorial flood loss estimation model FLEMO, which considers private precaution as a flood resistance parameter [37-38]. However, with regard to empirical information on property-level mitigation measures in Germany, current levels and loss mitigation effects of implemented measures are still only sporadically available and often limited to a specific region. Data on long-term developments of private precautionary behaviour, to gain insights into changes of people's vulnerability towards floods in the long run, are even less available (e.g. [29, 33-35, 39-41]). Though, a good knowledge about changes of vulnerability in the past is important to estimate future developments and their effects on flood losses [42-44]. Under the given circumstances, flood loss model derivation and validation remains a major challenge.

The lack of reliable and consistent empirical data is a general obstacle in flood risk modelling and one of the major sources of uncertainty. Often, observed data on flood losses or influencing parameters are only rarely available or are of different or insufficient quality and spatial resolution. Hence, the shape of the loss functions derived and adapted from these data can vary a lot (e.g. $[8,10,12,45])$. Further uncertainties are attributed to the associated assets of the risk elements [8, 15, 46] as well as the choice of scale [8], the cost basis (replacement costs or depreciated values) or the type of damage function (absolute or relative) [15]. Generally, model validation can help to assess the reliability of the model results (e.g. by comparing modelled losses to observed flood losses of a certain event). Yet, due to limited or even missing loss data, validation is only rarely performed [8]. Examples of a (successful) model validation are the investigations of [18-19, 38, 47-48], who all positively validated the flood loss model FLEMO (either for residential buildings, the commercial sector or further developments of that model) as well as [9, 15].

However, despite the sporadic opportunity to determine the accuracy of these models, flood loss models are often transferred to other flood events or regions to estimate current or future flood losses, which introduces another source of uncertainty $[8,10,12]$. This approach does not take into account changes in asset values or susceptibility of elements at risk, e.g. due to changes in preparedness of flood-prone residents. It is furthermore usually assumed that the relation between damage influencing parameters and losses are truly identical in all regions $[8,12]$. There are only few studies dealing with the assessment of flood loss model transferability (e.g., [9, 15-16, 38]) hinting that the underlying assumptions of model transferability might not be valid. For instance, [16] revealed, that additional explanatory variables besides the water depth improve the predictive capability in a spatial and temporal transfer context, i.e., when the models are transferred to different regions and different flood events. [9] clearly demonstrated that loss models are better transferable if the underlying empirical data are taken from region similar or near to the study area. Yet it is concluded that a temporal and spatial transferability of models is necessarily linked to an adjustment of the input data regarding the vulnerability of elements at risk and study site characteristics.

Therefore, on the basis of computer-aided telephone interviews with private households that suffered from property damage due to flooding in 2002 and/or 2013 in Germany, the overall aim of this study was to investigate whether the flood loss model FLEMO can be transferred in time and space. For this, models derived from one flood event and transferred to the other flood event were tested - with particular consideration of changes in property-level mitigation measures and loss reduction effects for residential buildings. The empirical data set provided a unique opportunity not only to compare the development and the impact of flood mitigation measures on building losses between the two flood events of 2002 and 2013 , but also to use the information to validate the loss model.

\section{Data and methods}

\subsection{Data basis for assessing changes in property-level mitigation measures and loss mitigation effects}

In order to improve the understanding of potential factors influencing flood losses to residential buildings, e.g. property-level flood mitigation measures or flood characteristics, computer-aided telephone interviews with residents that suffered from property damage caused by flooding in 2002 and/or 2013 in Germany were conducted about nine months after the respective flood event. Information on affected municipalities, flood reports or flood maps as well as lists of inundated streets 


\begin{tabular}{|c|c|c|}
\hline Flood event & Survey period & $\mathbf{n}$ \\
\hline August 2002 & 8 April - 10 June 2003 & \\
\hline May/June 2013 & 18 February - 24 March 2014 & \\
\hline \multicolumn{3}{|c|}{$\begin{array}{l}\text { Addressed topics: } \\
\text { - } \quad \text { flood impact characteristics } \\
\text { - } \quad \text { physical and financial flood losses (to residenti } \\
\text { buildings and household contents) } \\
\text { - } \quad \text { previously experienced floods } \\
\text { long-term private preventive and protective measures at } \\
\text { - } \quad \text { early warning } \\
\text { - } \quad \text { emergency measures } \\
\text { - } \quad \text { evacuation } \\
\text { - } \quad \text { contamination of the flood water } \\
\text { - } \quad \text { clean-up } \\
\text { - } \text { recovery of the affected household } \\
\text { - } \quad \text { general information on the residential building and } \\
\text { - } \text { intangible flood effects (only in 2013) } \\
\text { - } \quad \text { aid and financial compensation } \\
\text { socio-demographic variables }\end{array}$} \\
\hline
\end{tabular}

were compiled for each of the two flood events and telephone numbers of potentially affected households were searched from the public telephone directory. For the survey on the 2002 flood event, households were randomly selected from these lists, however, for the survey on the 2013 flood event, a comprehensive survey was carried out, i.e. all searched telephone numbers were contacted. In total, 1697 interviews were conducted for the 2002 flood event and 1652 for the 2013 flood event. The content of the two surveys differed only slightly. After the June 2013 flood, some questions were posed on intangible flood effects (e.g. health impairments) as well as on the assessment of the (governmental) aid for reconstruction. Table 1 provides an overview of the two interview campaigns and lists the addressed topics. A more detailed description of the surveys can be found in [5] or [39].

In order to evaluate how the precautionary behaviour of private households changed from 2002 to 2013, property-level mitigation measures implemented before and after the respective flood events were investigated in more detail. From a list of predefined precautionary measures, flood-affected residents were asked to indicate all measures that they had taken before or after each flood event and what measures they planned to take within the next six months. Multiple answers were possible [5]. Below the selection of property-level mitigation measures is listed, which were analysed in this study in more detail:

- $\quad$ adapted building use, e.g. no storage of valuable belongings in the cellar

- adapted furnishing/interior equipment, e.g. laying a water-resistant floor cover on the ground floor

- $\quad$ replace or secure oil heating

- put heating system upstairs

- $\quad$ seal the basement/building

- $\quad$ purchase water barriers
In the following, the respective answers were enumerated and compared between the two investigated flood events. In addition, the loss mitigation effect of each measure was calculated. We did so by comparing median building loss ratios (i.e. relative losses) of residents who had and who had not implemented this particular property-level mitigation measure. Significant differences between the two independent groups of data were tested by the Mann-Whitney-U-Test $(\mathrm{p}<0.05)$.

In order to compare resulting building losses of both flood events, building losses of 2002 were adjusted to the price level of 2013 by using the building cost index (index change from quarter II: August 2002 to quarter III: May 2013: value 1.25 [49]).

\subsection{Derivation and adaptation of the flood loss model}

The flood loss model FLEMO is one of few models that also includes precautionary measures as an input parameter. This empirical model was developed at the GFZ German Research Centre for Geosciences and at first derived from 1697 collected flood damage data of private households in the German federal states of Saxony, Saxony-Anhalt and Bavaria, which were affected by the flood of August 2002 (compare Table 1). In total, the multi-parameter model considers five different loss influencing parameters (Table 2). In a base version, the direct monetary loss for residential buildings is calculated based on five water depth classes, three building type classes and two building quality classes. In an extended version (FLEMO+) scaling factors of various combinations of contamination of the flood water and private precautionary measures can also be [37-38]. The loss model can be applied on building level (micro-scale) as well as on land use level (meso-scale) [38]. For this study it was applied on the micro-scale.

The investigation and validation whether FLEMO can be derived from one flood event and applied to another flood event - with particular consideration of changes in property-level mitigation measures and loss reduction effects for residential buildings - was carried out on the basis of two different model runs following the idea of a split sampling approach (Figure 1). However, prior to the

\begin{tabular}{lll}
\hline Model & Parameter & Classification \\
\hline & & $<20 \mathrm{~cm}$ \\
& & $21-60 \mathrm{~cm}$ \\
& Water level & $61-100 \mathrm{~cm}$ \\
& & $101-150 \mathrm{~cm}$ \\
FLEMO & & $>150 \mathrm{~cm}$ \\
\cline { 2 - 3 } (base model) & Building type & One-family house \\
& & Semi-detached house \\
& & Multi-family house \\
\cline { 2 - 3 } & \multirow{2}{*}{ Building quality } & Poor/medium \\
& & High \\
\hline \multirow{2}{*}{ FLEMO+ } & & No \\
& Private precaution & Good \\
& & Very good \\
\cline { 2 - 3 } & \multirow{2}{*}{ Contamination of } & No \\
& the flood water & Low $/$ medium \\
& & High \\
\hline
\end{tabular}

Table 2. FLEMO input parameters [38]. 


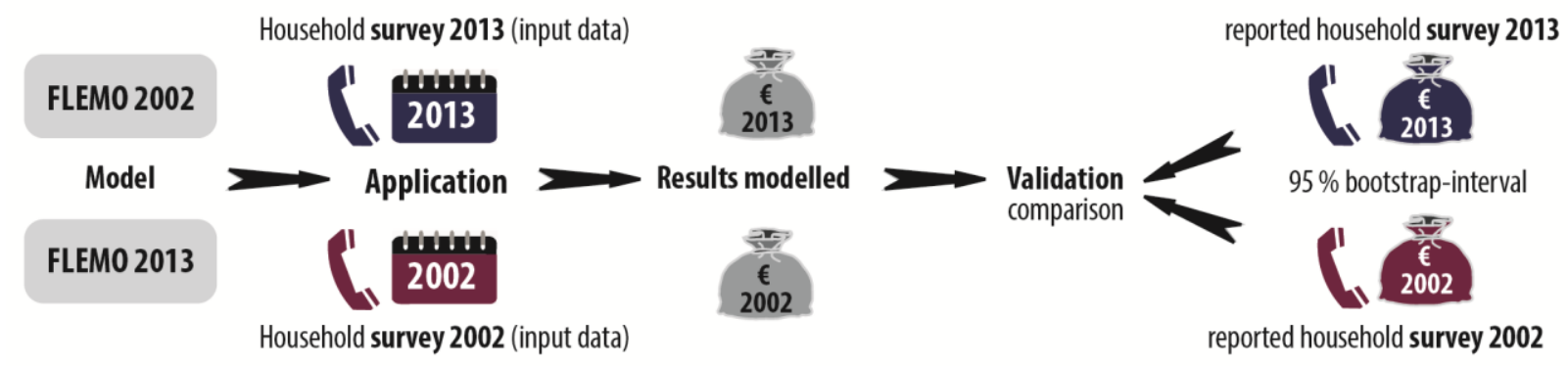

Figure 1. Flow chart of the two model validation processes.

analyses, some modifications of the current FLEMO model, which was derived from the household survey of 2002, had to be made. When applying FLEMO in an earlier study, [38] found out that the model fails to estimate building losses caused by very high water levels, for example, flooding of the first floor. Therefore, we introduced a sixth water level class $(>400 \mathrm{~cm})$, which represents very high inundation. Furthermore, the two input parameters private precaution and contamination of the flood water had been redefined: Precautionary measures that were considered in the extended model FLEMO+ so far included measures like information and behavioural precaution (e.g. collecting information about the flood hazard and protection, as well as participation in networks), risk precaution (e.g. concluding a flood insurance) and property-level mitigation measures (e.g. adaptation of building use and furniture or replacement of heating system). Gathering information or contracting insurance are important elements of private precaution, yet do not result in loss reduction in the first place. Only the implementation of preventive, protective or preparatory measures, in particular property-level mitigation measures, will have the intended effect. For this reason, an adapted precaution factor was implemented in the model, which considers only property-level mitigation measures (classified according to the number and type of implemented measures). The six considered mitigation measures are listed in section 2.1. In addition, the contamination factor, which includes sewage, chemical or oil/petrol contamination of the flood water was reclassified. Once respondents suffered from oil or petrol contamination, a high contamination level was now always assumed. In the previous model, oil contamination could also be classified as medium contamination. On the basis of the two newly defined and classified input parameters, scaling factors for adjusting building losses were recalculated. The adapted model is hereinafter referred to as FLEMO2002 (base model) and FLEMO2002+ (extended model).

In a first approach, FLEMO2002 and FLEMO2002+ were now applied to the data of the 2013 flood event. All needed information for the input parameters were derived from the household survey of 2013. However, only the subset of interviews with complete information on input parameters and reported losses was considered. The resulting modelled buildings losses were then compared to the building losses reported by the interviewed residents in 2013 (Figure 1). As a measure for acceptable loss estimations and rating tool for the overall model accuracy, a bootstrap procedure with 10,000 random samples with replacement was applied to all reported building loss data. In accordance with [38] and [9], the 2.5th and 97.5th percentile of the total, mean and median building loss were hence calculated to obtain a $95 \%$ confidence interval of the reported building loss records. Eventually, all modelled building losses that fell within this bootstrap interval were assumed to be acceptable.

In a second approach, the temporal transferability of FLEMO was retested. Similar to the derivation of the base and extended FLEMO2002 model, the model was now newly derived from the household survey of 2013 (hereinafter referred to as FLEMO2013 and FLEMO2013+) and applied to the data of the 2002 flood event. Information of the household survey of 2002 served as input data for the model to see whether the new model was also suitable to estimate building losses of past flood events (Figure 1). Again, only the subset of interviews with complete information on input parameters and reported losses was considered. In order to compare building losses of both flood events, building losses of 2002 were adjusted to the price level of 2013 by the building cost index of May 2013 [49]. Model validation was also carried out analogously to the first approach, based on the comparison of the modelled building losses and losses reported by floodaffected residents in 2002 using bootstrapping.

To get greater confidence in the quality of the newly derived model FLEMO2013, the model was previously derived from the half of the survey data of 2013 and then applied on the other half of the 2013 data (split sampling technique). The model is hereinafter referred to as FLEMO2013split and FLEMO2013split+. Model validation was performed as described above.

\section{Results and discussion}

The following section first describes the results of the household surveys 2002 and 2013 with respect to the changes in property-level mitigation measures and loss mitigation effects. Subsequently, the results of the two loss modelling approaches are represented. 


\subsection{Changes in property-level mitigation measures and loss mitigation effects}

Figure 2 provides an overview of property-level mitigation measures performed by flood-affected residents before and after the flood in 2002 or 2013 and measures planned for the next six months. It is striking that respondents interviewed in 2013 consistently performed precautionary measures more frequently before the flood than respondents interviewed in 2002. In 2013, about $58 \%$ of respondents implemented at least one property-level mitigation measure. The corresponding proportion or respondents in 2002 amounted to only $29 \%$. The latter group of people, however, increased their precautionary measures very extensively after the flood event. The gained flood experience and greater risk awareness probably play a major role in this context. After the 2002 flood, many affected residents felt motivated to implement mitigation measures in the future, with the result that flood-proofing and building retrofitting measures were significantly more pronounced before the 2013 flood.

Prior to the floods of 2002 and 2013, the most commonly performed property-level mitigation measures were the adaptation of building use $(13 \%$ and $36 \%$, respectively) or interior equipment (13\% and $34 \%$, respectively). In these cases, flood-prone building floors are used only inferior and accordingly furnished with water resistant materials. Furthermore, with sufficient lead time mobile water barriers can be set up to further protect the building from the flood (amongst others stop log systems or sandbags). However, the measure effectiveness is only maintained as long as the barriers will not be submerged. After all, in the run-up to the flood events of 2002 and 2013, respectively $9 \%$ and $15 \%$ of the respondents purchased mobile water barriers. The Pentecost flood in May 1999 and the August 2002 flood have shown that leaking fuel oil can significantly increase building losses by two to three times $[29,50]$. Therefore, and in order to avoid environmental damage, the relocation of heating systems or the securing of fuel oil tanks is of particular importance in flood-prone areas. Figure 2 shows that the share of respondents who carried out corresponding measures more than doubled over the years. For example, before the 2002 flood only $5 \%$ of respondents installed a flood-proof heating system. Before the 2013 flood, this share amounted at least $12 \%$. A similar development can be identified for the measure strengthening the building foundation by sealing the basement. In 2002, about $6 \%$ of respondents performed this measure, whereas in 2013 , this share increased to $13 \%$.

However, the increase in property-level mitigation measures was not automatically accompanied by a reduction of building losses. The median building loss reported by all flood-affected interviewees of the two flood events was in fact identical with about EUR 30,000, respectively (building losses in 2002 indexed to May 2013 by the building price index). The survey outcome is surprising in that sense that the respondents in 2013 had not only carried out more

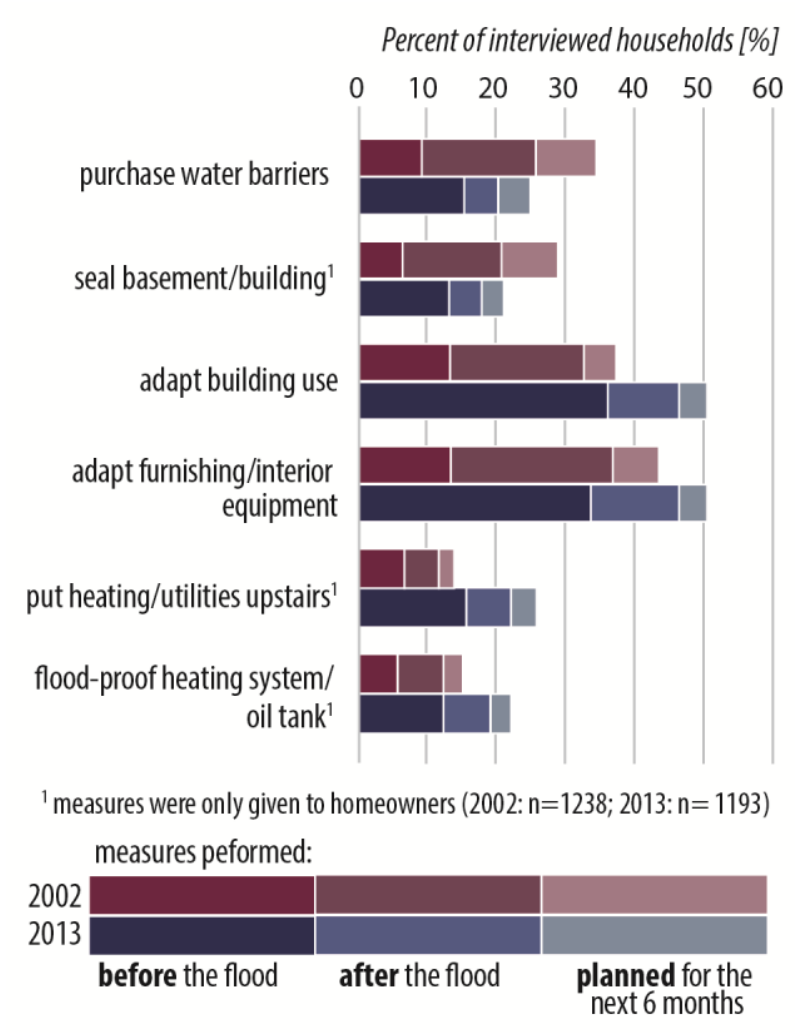

Figure 2. Property-level mitigation measures performed by flood-affected residents before and after the flood in 2002 or 2013 and measures planned for the next six months (multiple answers possible).

property-level mitigation measures before the flood, but that in this year the knowledge about the potential hazard, personal concern and possibilities how to protect themselves was much better than in 2002 [5]. Moreover, the reported median water level at the buildings was significantly lower in $2013(40 \mathrm{~cm})$ than in $2002(65 \mathrm{~cm})$. Also early warning distribution and the median lead time was enhanced, so people had more time to respond to the flood [5]. From these aspects it could be concluded that building losses of the 2013 flood were lower than building losses of the 2002 flood, though this was not verified by the survey data. One reason might be that flood-affected buildings were on average of more value in 2013 than in 2002 (the inflation-corrected median building value in 2002 amounted to EUR 390,000 and in 2013 to EUR 428,000). This might result in higher building losses for the same water levels and accordingly limits the overall loss mitigation.

Also surprising in this context was that the loss reducing effect of the single property-level mitigation measures turned out to be more effective in 2002 than in 2013. The overall most effective measures in both flood events were the adaptation of building use (Figure 3) and furnishing. Compared to respondents who had not carried out these measures, the median building loss ratio decreased significantly in 2002 by $74 \%$ (adapted building use) and $80 \%$ (adapted furnishing). In absolute terms, the respective median loss decreased by EUR 27,500 and EUR 29,000. In 2013, these two measures were the only ones, which caused significant 


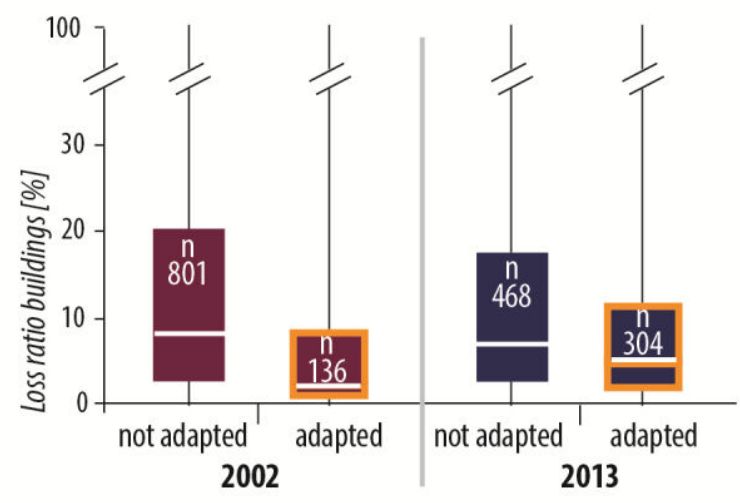

Figure 3. Significant loss mitigation due to adapted building use of flood-affected residents in 2002 and 2013.

loss reduction at all, yet the mitigation effect was much lower than in 2002. The corresponding median building loss ratio decreased by $24 \%$ (adapted building use) and $23 \%$ (adapted furnishing) only, resulting in respective median loss savings of EUR 10,000 and EUR 6,700. The installation of a flood-proof heating system or securing the oil tank was also among the best loss mitigating measures in 2002. The median building loss ratio significantly decreased by $65 \%$ (absolute median savings of about EUR 19,000). In 2013, there was no statistical difference in building losses for residents who had and who had not implemented this measure. An explanation might be that in 2002 a higher percentage of respondents was affected by severe oil or petrol contamination than in 2013 (38\% compared to $18 \%$ ) and therefore the loss mitigation effect of flood-proof heating systems became more evident. Furthermore, it must be taken into account that neighbours also benefit from securing the oil tank, since leaking fuel oil will no longer pollute their houses as well. As the share of people who secured their oil tank increased in 2013, this interrelation might have played a role regarding the measure's loss mitigation effect in 2013. Sealing the basement roughly halved the building loss ratio in 2002 and reduced the absolute median loss by about EUR 18,000. However, again no significant loss mitigation effect of this measure could be identified in 2013. The setup of mobile barriers resulted in a significantly decreased median building loss ratio in 2002 (about $43 \%$, median savings of about EUR 16,000). In 2013, changes in median building loss ratios due to available mobile barriers were not significant. Maybe more barriers were flooded during the 2013 event due to local high water levels or time was lacking to setup barriers, e.g. due to fast onset flooding, which can cause substantial losses and hence diminished loss mitigation [34-35, 51].

Reasons for a less effective loss reduction in 2013 might be that local conditions like regional flood dynamics (river flood, rapid-onset flood, groundwater inundation) played an influencing role. In this context, [4] and [32] confirm that not every precautionary measure is likewise effective for different flood types. For example, the implementation and effectiveness of some measures strongly depend on sufficient lead time (e.g. mobile barriers), which is usually higher for river floods than for flash floods. In addition, measures like sealing the basement are mainly effective as long as the basement does not need to be flooded to counteract buoyancy forces [4, 27]. Maybe the overall loss mitigation effect of the respective measures was hence masked due to no spatially differentiated analysis of loss claims in this study. Another reason might be that the improved early warning and opportunity to carry out emergency measures enabled a lot more respondents without any property-measure mitigation measures to reduce their losses than in 2002. Hence, loss differences to respondents who implemented mitigation measures were smaller in 2013. Finally, the implementation quality and consequential effectiveness of the propertylevel mitigation measures as well as reported building loss records can hardly be verified using questionnaire data. These kinds of information are generally a major source of uncertainty. However, since a consistent questionnaire was used for both surveys, the methodological error could at least be minimized. It cannot be excluded however, that respondents in 2013 reported higher levels of precaution due to the public debate on having not learned enough from the 2002 flood and the consequent anticipated social desirability of answers.

\subsection{Modelled building losses}

\subsubsection{Model derivation}

The respective mean building loss ratios (of buildings with poor or average building quality) derived from the household survey data of 2002 and 2013 and hence used in the two flood loss models FLEMO2002, FLEMO2013 and the split sampled model FLEMO2013split are displayed in Table 3. The respective values for buildings with high building quality were calculated by multiplying the mean loss ratios of buildings with poor/average quality with separate loading factors as listed in Table 4. Following [37], these factors were also derived from the respective household surveys.

Both in FLEMO2002 and FLEMO2013 the mean building loss ratio differentiated according to building types and quality increased with increasing water levels from minimum $2 \%$ to maximum $46 \%$ (data not shown). Furthermore, it needs to be emphasized that in both household surveys, only very few loss records for water levels of more than $400 \mathrm{~cm}$ existed (see Table 3). Accordingly, the reliability of calculated building loss ratios associated with high inundation needs to be regarded with caution. Despite these drawbacks, depthdamage functions of FLEMO2002 and FLEMO2013 turned out to be quite similar, only loss ratios of the FLEMO2013 model with high building quality were predominantly slightly higher. Highest deviation of building loss ratios amounted to 12 percentage points (recorded between one-family houses of high building quality, data not shown). Building loss ratios of the FLEMO2013split model were similar to the values 


\begin{tabular}{|c|c|c|c|c|c|c|c|}
\hline \multirow[b]{2}{*}{ Building type } & \multirow[b]{2}{*}{$\begin{array}{l}\text { Classified water level } \\
{[\mathrm{cm}]}\end{array}$} & \multicolumn{2}{|c|}{ FLEMO2002 } & \multicolumn{2}{|c|}{ FLEMO2013 } & \multicolumn{2}{|l|}{ FLEMO2013split } \\
\hline & & $\begin{array}{l}\text { Mean building } \\
\text { loss ratio }\end{array}$ & $\mathbf{n}$ & $\begin{array}{l}\text { Mean building } \\
\text { loss ratio }\end{array}$ & $\mathbf{n}$ & $\begin{array}{c}\text { Mean building loss } \\
\text { ratio }\end{array}$ & $\mathbf{n}$ \\
\hline \multirow{6}{*}{ One-family house } & $<21$ & 0.04 & 143 & 0.04 & 142 & 0.05 & 71 \\
\hline & $21-60$ & 0.07 & 44 & 0.10 & 52 & $0.10^{*}$ & 59 \\
\hline & $61-100$ & 0.10 & 49 & 0.13 & 54 & $0.10^{*}$ & 59 \\
\hline & $101-150$ & 0.21 & 58 & 0.15 & 33 & 0.16 & 15 \\
\hline & $151-400$ & $0.24 *$ & 91 & $0.27 *$ & 54 & $0.25 *$ & 32 \\
\hline & $>400$ & $0.24 *$ & 91 & $0.27 *$ & 54 & $0.25^{*}$ & 32 \\
\hline \multirow{6}{*}{ Semi-detached house } & $<21$ & 0.03 & 58 & 0.05 & 94 & 0.04 & 47 \\
\hline & $21-60$ & 0.08 & 20 & $0.11^{*}$ & 44 & $0.13^{*}$ & 21 \\
\hline & $61-100$ & 0.11 & 16 & $0.11 *$ & 44 & $0.13 *$ & 21 \\
\hline & $101-150$ & 0.18 & 17 & 0.17 & 17 & $0.14^{*}$ & 31 \\
\hline & $151-400$ & 0.19 & 45 & 0.19 & 37 & $0.14^{*}$ & 31 \\
\hline & $>400$ & 0.40 & 6 & 0.41 & 6 & 0.35 & 3 \\
\hline \multirow{6}{*}{ Multi-family house } & $<21$ & 0.03 & 81 & 0.02 & 22 & $0.02 *$ & 19 \\
\hline & $21-60$ & 0.10 & 34 & 0.03 & 14 & $0.02 *$ & 19 \\
\hline & $61-100$ & 0.10 & 23 & $0.10^{*}$ & 19 & $0.10^{*}$ & 13 \\
\hline & $101-150$ & 0.13 & 34 & $0.10^{*}$ & 19 & $0.10^{*}$ & 13 \\
\hline & $151-400$ & $0.19^{*}$ & 48 & 0.16 & 23 & $0.20 *$ & 15 \\
\hline & $>400$ & $0.19^{*}$ & 48 & 0.18 & 3 & $0.20 *$ & 15 \\
\hline
\end{tabular}

Table 3. Mean loss ratios of buildings with poor/average building quality derived for the flood loss models FLEMO2002 and FLEMO2013, differentiated according to building types and water level classes.

\begin{tabular}{lccc}
\hline & \multicolumn{3}{c}{ Loading factors } \\
\cline { 2 - 4 } Building type & FLEMO & FLEMO & FLEMO \\
& $\mathbf{2 0 0 2}$ & $\mathbf{2 0 1 3}$ & $\mathbf{2 0 1 3 s p l i t}$ \\
\hline One-family house & 1.17 & 1.55 & 1.59 \\
Semi-detached house & 1.13 & 1.11 & 1.11 \\
Multi-family house & 1.45 & 1.81 & 2.5 \\
\hline
\end{tabular}

Table 4. Loading factors for calculating loss ratios of buildings with high building quality.

of the FLEMO2013 model. However, many water level classes had to be merged due to overall only few available data.

For the extended models FLEMO2002+ and FLEMO2013+, the combination of flood water contamination and precaution (property-level mitigation measures) per data record was used to multiply the corresponding loss of FLEMO2002 and FLEMO2013 with the empirically derived scaling factor (Table 5). It is assumed that no high contamination can occur if there is at least a good level of property-level mitigation measures. Furthermore, when deriving scaling factors it was considered that the factor decreased with improved property-level mitigation measures. If this was not the case, classes had been combined and an average factor calculated (e.g. for the combination of no contamination and good/very good property-level mitigation measures, Table 5). When comparing the single scaling factors of FLEMO2002+ and FLEMO2013+ it revealed that the factors of FLEMO2013+ were consistently higher. Consequently, the building loss reduction due to property-level mitigation measures was always lower than for the FLEMO2002+ model, as was already highlighted above for single measures. The outcome of the scaling factors is at least consistent with the survey results (see section 3.1).

\begin{tabular}{llccc}
\hline $\begin{array}{l}\text { Conta- } \\
\text { mination }\end{array}$ & Precaution & $\begin{array}{c}\text { FLEMO } \\
\text { 2002+ }\end{array}$ & $\begin{array}{c}\text { FLEMO } \\
\text { 2013+ }\end{array}$ & $\begin{array}{c}\text { FLEMO } \\
\text { 2013split+ }\end{array}$ \\
\hline \multirow{3}{*}{ no } & no/low & 0.86 & 0.89 & 0.96 \\
& good & 0.54 & 0.60 & 0.61 \\
& very good & 0.54 & 0.58 & 0.61 \\
\hline \multirow{2}{*}{ low/ } & no/low & 0.95 & 1.10 & 1.26 \\
medium & good & 0.91 & 1.09 & 1.26 \\
& very good & 0.80 & 0.87 & 1.05 \\
\hline \multirow{2}{*}{ high } & no/low & 1.37 & 1.49 & 1.45 \\
& good & - & - & - \\
& very good & - & - & - \\
\hline
\end{tabular}

Table 5. Scaling factors for residential building losses, considering contamination of the flood water and precaution (property-loss mitigation measures).

\subsubsection{Comparison of the modelled and reported building flood losses}

In the following, the model results of the first approach will be described. The sum, mean and median of the overall building loss reported by the 635 floodaffected interviewees in 2013 amounted to EUR 34.0 million, EUR 53,603 and EUR 25,000, respectively. The performance of FLEMO2002 and FLEMO2002+ to estimate observed losses within a $95 \%$ bootstrap interval is displayed in Table 6 (top). It turned out that the extended model outperformed the base model. In contrast to FLEMO2002, FLEMO2002+ was able to reproduce not only the sum, but also the mean and median of the reported loss of 2013 within the given confidence interval and was thus successfully validated. This result clearly shows that the consideration of property-level mitigation measures in loss models provides better approximations to building losses than models that are limited to only few influencing parameters.

This outcome is in line with other studies on multifactorial flood loss models (e.g. [16, 17, 19]). 


\begin{tabular}{|c|c|c|c|c|c|c|}
\hline Model & & $\begin{array}{c}\text { Sum } \\
{[\mathrm{m} . \text { Euro] }}\end{array}$ & $\begin{array}{l}\text { Mean } \\
\text { [Euro] }\end{array}$ & $\begin{array}{c}\text { Median } \\
\text { [Euro] }\end{array}$ & $\mathbf{n}$ & $\begin{array}{c}\text { MAE } \\
\text { [Euro] }\end{array}$ \\
\hline \multirow{4}{*}{ FLEMO2002 } & $\begin{array}{l}\text { Reported building loss } \\
\text { (interviews 2013) }\end{array}$ & 34.0 & 53,603 & 25,000 & \multirow[t]{2}{*}{635} & \\
\hline & $95 \%$ bootstrap interval & $30.0-38.5$ & $47,174-60,554$ & $23,000-30,000$ & & \\
\hline & FLEMO2002 & 40.2 & 63,246 & 34,052 & 635 & 48,150 \\
\hline & FLEMO2002+ & 35.2 & 55,486 & 28,441 & 635 & 41,325 \\
\hline \multirow{4}{*}{ FLEMO2013split } & $\begin{array}{l}\text { Reported building loss } \\
\text { (split sampled interviews 2013) }\end{array}$ & 18.4 & 58,692 & 27,000 & \multirow[t]{2}{*}{313} & \\
\hline & $95 \%$ bootstrap interval & $15.1-22.1$ & $48,076-70,813$ & $23,000-30,000$ & & \\
\hline & FLEMO2013split & 22.2 & 70,832 & 40,338 & 313 & 58,161 \\
\hline & FLEMO2013split+ & 23.4 & 74,639 & 41,109 & 313 & 56,969 \\
\hline \multirow{4}{*}{ FLEMO2013 } & $\begin{array}{l}\text { Reported building loss } \\
\text { (interviews 2002) }\end{array}$ & 45.1 & 51,745 & 31,257 & \multirow[t]{2}{*}{871} & \\
\hline & $95 \%$ bootstrap interval & $41.3-49.0$ & $47,413-56,274$ & $25,006-32,508$ & & \\
\hline & FLEMO2013 & 49.5 & 56,813 & 41,298 & 871 & 29,871 \\
\hline & FLEMO2013+ & 61.1 & 70,162 & 43,789 & 871 & 34,614 \\
\hline
\end{tabular}

Table 6. Comparison of modelled and reported building flood losses (including $95 \%$ bootstrap interval) for the different model approaches and the flood events of 2002 and 2013.

However, despite the good performance of FLEMO2002+, the mean absolute error (MAE) of the model estimates was still very high, amounting to about EUR 41,300. Previous transferability studies of FLEMO+ also revealed high uncertainty regarding the loss estimates. [38] used the primary model for calculating building losses of five municipalities in Saxony affected by the August 2002 flood in the Elbe catchment and five municipalities in BadenWürttemberg affected by the December 1993 flood in the Neckar catchment in Germany. The outcome was that the mean relative error for the 2002 flood loss estimates amounted to $24 \%$ whereas it increased to even more than $1000 \%$ for the 1993 flood. The improved transferability of the FLEMO2002+ model might be due to a greater similarity of the flood characteristics of the investigated flood events 2002 and 2013 in comparison to 2002 and 1993, and regional study site characteristics might have been better represented on average due to the comparable spatial extents of the events.

Before the results of the second approach will be described in more detail, it had to be clarified whether the split sampled model FLEMO2013split was even able to calculate losses of the 2013 flood and hence if the subsequent applied FLEMO2013 model was generally reliable. The results of the model performance are also summarized in Table 6 (centre). In fact it was found that neither the base model nor the extended model FLEMO2013split+ was able to estimate the sum, mean or median of the observed building losses of 2013 within the $95 \%$ bootstrap interval. Though, the base model's results were only slightly higher than the upper confidence interval boundary. Nevertheless, it cannot be stated that the model was successfully validated and is truly appropriate for assessing building losses in the second model approach. Yet it has to be acknowledged that the model derivation had to be based on only few data, which probably also influenced the overall model quality.

The loss model validation based on the second approach was hence (also) not successful. The sum, mean and median of the overall building loss reported by the 871 flood-affected interviewees in 2002 amounted to EUR 36.0 million, EUR 41,386 and EUR 25,000 , respectively. Like it was the case for the FLEMO2013split model validation, neither the FLEMO2013 nor the FLEMO2013+ model was able to estimate the observed building losses within the $95 \%$ bootstrap interval, but constantly overestimated the losses (Table 6, bottom). And again, the base model performed a bit better than the extended model, since the estimated total and mean loss were at least only slightly higher than the upper boundary of the confidence interval. Yet, it was comprehensible that the estimated building loss of the FLEMO2002+ model was higher than of the FLEMO2002 model since the level of precaution in 2002 is characterized by low propertylevel mitigation measures and medium to high flood water contamination. Hence, the loss increase due to contamination could not be compensated by few mitigation measures. However, we assume that the poor performance of FLEMO2013+ was partly due to the values of the derived scaling factors or rather the underlying database, which did not reflect the overall assumption that the improved level of property-level mitigation measures in 2013 reduced losses to a higher degree than in 2002.

\section{Conclusions}

Despite a few exceptions, the common models that are used for flood loss assessments today rarely include multiple loss influencing factors and are often transferred in time and space to other flood events or regions without being able to verify to what extent this actually results in reliable estimates. This study therefore aimed at investigating the spatio-temporal transferability of the multifactorial flood loss estimation model FLEMO from one flood event to another, using the examples of the August 2002 and May/June 2013 flood events in Germany, with particular consideration of changes in property-level mitigation measures and loss reduction effects for residential buildings. 
Regarding flood loss modelling, the importance to include more loss influencing factors than only the water level, particularly property-level mitigation measures, could be confirmed. However, by transferring the model to another flood event, changes in propertylevel mitigation measures and resulting building losses could only be partially reproduced (FLEMO2002+) and model errors remained very high. These results indicate that flood loss influencing processes and factors are still not yet sufficiently understood and represented in models due to complex interrelations and different flood and site specific characteristics. This could also be shown on the basis of the evaluation of changes in property-level mitigation measures. The empirical data indicated that the share of implemented measures increased a lot since 2002. Accordingly, flood-prone residents are nowadays better prepared for future floods than it was the case before the flood in 2002. However, the potential of enhancing mitigation measures appears to be not yet exhausted. This is confirmed by studies from other regions [41]. Improvements are especially needed in areas that are rarely affected by flooding. Though, in contrast to the assumption that an increased level of property-level mitigation measures reduces building losses more strongly, the average building loss as well as loss mitigation effects of implemented measures in 2013 was similar to or even lower than in 2002. Maybe the loss mitigation influence of precautionary measures is less important with the development of an improved early warning like in 2013. In order to improve the assessment of mitigation effects, a regression analysis could be performed as this method can provide better insights into interrelationships of measures and is hence more suitable than the loss comparison of groups who carried out measures and who did not [32]. In addition, the effectiveness depends on local flood dynamics. Therefore, it might be promising to differentiate property-level mitigation measures and respective loss reducing effects according to different flood types. Since the flood dynamic influence thereby also might have played a role regarding the different model performances, it would be interesting to repeat the model transfer and validation for different flood types.

Overall, the results of this study confirmed that the temporal and spatial transferability of flood loss models remains very uncertain, which should be taken into account and communicated by model users. More research on changes in loss explanatory parameters, preferably within regions of similar site characteristics and standardised data collection is needed to understand damage processes and to validate flood loss models.

\section{References}

1. Hattermann F. F., Huang S., Vetter T., Kron W., Burghoff O., Merz B., Bronstert A., Krysanova V., Gerstengarbe F.-W., Werner P. and Hauf Y. (2012). Flood risk from a holistic perspective - observed changes in Germany. In: Kundzewicz Z. W. (eds.).
Changes in flood risk in Europe. CRC Press. 212237.

2. Hattermann F. F., Huang S., Burghoff O., Willems W., Österle H., Büchner M. and Kundzewicz Z. (2014). Modelling flood damages under climate change conditions - a case study for Germany. Natural Hazards and Earth System Sciences, 14(12), 3151-3168.

3. Höppe P. (2014) Naturkatastrophen der letzten Jahrzehnte. Trends bei Häufigkeit und Schäden, Ausblick in die nahe Zukunft. Natur und Landschaft, 89(12), 516-521.

4. Kreibich H., Bubeck P., Kunz M., Mahlke H., Parolai S., Khazai B., Daniell J., Lakes T. and Schröter K. (2014). A review of multiple natural hazards and risks in Germany. Natural Hazards, 74(3), 2279-2304.

5. DKKV (German Committee for Disaster Reduction) (2015): Das Hochwasser im Juni 2013: Bewährungsprobe für das Hochwasserrisikomanagement in Deutschland. DKKV-Schriftenreihe, No. 53, 207 p. (in German).

6. Thieken A. H., Petrow T., Kreibich H. and Merz B. (2006). Insurability and Mitigation of Flood Losses in Private Households in Germany. Risk Analysis, 26(2), 383-395.

7. Thieken, A. H., Müller, M., Kreibich, H., Merz, B. (2005): Flood damage and influencing factors: New insights from the August 2002 flood in Germany. Water Resources Research 41(12): W12430.

8. Merz B., Kreibich H., Schwarze R. and Thieken A. H. (2010). Review article "Assessment of economic flood damage". Natural Hazards and Earth System Sciences, 10, 1697-1724.

9. Cammerer H., Thieken A. H. and Lammel J. (2013). Adaptability and transferability of flood loss functions in residential areas. Natural Hazards and Earth System Sciences, 13(11), 3063-3081.

10. Meyer V., Becker N., Markantonis V., Schwarze R., van den Bergh J. C. J. M., Bouwer L. M., Bubeck P., Ciavola P., Genovese E., Green C., Hallegatte S., Kreibich H., Lequeux Q., Logar I., Papyrakis E., Pfurtscheller C., Poussin J., Przyluski V., Thieken A. H. and Viavattene C. (2013). Review article: Assessing the costs of natural hazards - state of the art and knowledge gaps. Natural Hazards and Earth System Sciences, 13(5), 1351-1373.

11. Messner F., Penning-Rowsell E., Green C., Meyer V., Tunstall S. and van der Veen A. (2007). Evaluating flood damages: guidance and recommendations on principles and methods. FLOODsite-Report, T09-06-01, 176 p.

12. Bubeck P. and Kreibich H. (2011). Natural hazards: direct costs and losses due to the disruption of production processes. CONHAZ Report, WP1, 68 p.

13. de Moel H. and Aerts J. C. J. H. (2011). Effect of uncertainty in land use, damage models and inundation depth on flood damage estimates. Natural Hazards, 58(1), 407-425. 
14. Green C., Viavattene C. and Thompson P. (2011). Guidance for assessing flood losses: CONHAZ report, WP6, $86 \mathrm{p}$.

15. Jongman B., Kreibich H., Apel H., Barredo J. I., Bates P. D., Feyen L., Gericke A., Neal J., Aerts J. C. J. H. and Ward P. J. (2012). Comparative flood damage model assessment: towards a European approach. Natural Hazards and Earth System Sciences, 12, 3733-3752.

16. Schröter K., Kreibich H., Vogel K., Riggelsen C., Scherbaum F. and Merz B. (2014). How useful are complex flood damage models? Water Resources Research, 50(4), 3378-3395.

17. Apel H., Aronica G. T., Kreibich H. and Thieken A. H. (2009). Flood risk analyses - how detailed do we need to be? Natural Hazards, 49(1), 79-98.

18. Wünsch A., Herrmann U., Kreibich H. and Thieken A.H. (2009). The Role of Disaggregation of Asset Values in Flood Loss Estimation: A Comparison of Different Modeling Approaches at the Mulde River, Germany. Environmental Management, 44(3), 524-541.

19. Elmer F., Thieken A. H., Pech I. and Kreibich H. (2010). Influence of flood frequency on residential building losses. Natural Hazards and Earth System Sciences, 10, 2145-2159.

20. Wasserhaushaltsgesetz (Federal Water Act) (2009). "Wasserhaushaltsgesetz vom 31. Juli 2009 (BGB1. I S. 2585), das zuletzt durch Artikel 320 der Verordnung vom 31. August 2015 (BGB1. I S. 1474) geändert worden ist (in German).

21. Dawson R.J., Ball T., Werritty J., Werritty A., Hall J.W. and Roche N. (2011). Assessing the effectiveness of non-structural flood management measures in the Thames Estuary under conditions of socio-economic and environmental change. Global Environmental Change, 21, 628-646.

22. Poussin J. K., Bubeck P., Aerts J. C. J. H. and Ward P. J. (2012). Potential of semi-structural and non-structural adaptation strategies to reduce future flood risk: case study for the Meuse. Natural Hazards and Earth System Sciences, 12(11), 34553471.

23. de Moel H., van Vliet M. and Aerts J. C. J. H. (2014). Evaluating the effect of flood damagereducing measures: a case study of the unembanked area of Rotterdam, the Netherlands. Regional Environmental Change, 14(3), 895-908.

24. Lasage R., Veldkamp T. I. E., de Moel H., Van T. C., Phi H. L., Vellinga P. and Aerts J. C. J. H. (2014). Assessment of the effectiveness of flood adaptation strategies for HCMC. Natural Hazards and Earth System Sciences, 14(6), 1441-1457.

25. ABI (Association of British Insurers) (2003). Assessment of the Cost and Effect on Future Claims of Installing Flood Damage Resistant Measures, London.

26. Defra (Department for Environment, Food and Rural Affairs) (2008). Developing the evidence base for flood resistance and resilience. Joint Defra/EA Flood and Coastal Erosion Risk
Management R\&D Programme, FD2607/TR1, 24 p.

27. ICPR (International Commission for the Protection of the Rhine) (2002). Non structural flood plain management: Measures and their effectiveness. 50 p.

28. BMVI (Federal Ministry of Transport and Digital Infrastructure) (2013). Hochwasserschutzfibel Objektschutz und bauliche Vorsorge. $56 \mathrm{p}$ (in German).

29. Kreibich H., Thieken A. H., Petrow T., Müller M. and Merz B. (2005). Flood loss reduction of private households due to building precautionary measures - lessons learned from the Elbe flood in August 2002. Natural Hazards and Earth System Sciences, 5, 117-126.

30. Kreibich H. and Thieken A.H. (2009). Coping with floods in the city of Dresden, Germany. Natural Hazards, 51, 423-436.

31. Hudson P., Botzen W., Kreibich H., Bubeck P. and Aerts J. (2014). Evaluating the effectiveness of flood damage mitigation measures by the application of propensity score matching. Natural Hazards and Earth System Sciences, 14, 17311747.

32. Poussin J. K., Botzen W. J. W. and Aerts J. C. J. H. (2015). Effectiveness of flood damage mitigation measures: Empirical evidence from French flood disasters. Global Environmental Change, 31, 7484.

33. Bubeck P., Botzen W. J. W., Kreibich H. and Aerts J. C. J. H. (2012). Long-term development and effectiveness of private flood mitigation measures: an analysis for the German part of the river Rhine. Natural Hazards and Earth System Sciences, 12, 3507-3518.

34. Kreibich H., Christenberger S. and Schwarze R. (2011). Economic motivation of house-holds to undertake private precautionary measures against floods. Natural Hazards and Earth System Sciences, 11, 309-321.

35. Kreibich H., Christenberger S. and Schwarze R. (2012). Corrigendum to "Economic motivation of households to undertake private precautionary measures against floods", published in Natural Hazards and Earth System Sciences, 11: 309-321, 2011. Natural Hazards and Earth System Sciences, 12, 391-392.

36. Thieken A.H., Cammerer H., Dobler C., Lammel J., Schöberl F. (2014). Estimating changes in flood risks and benefits of non-structural adaptation strategies - a case study from Tyrol, Austria. Mitigation and Adaptation Strategies for Global Change, online first 31 October 2014.

37. Büchele B., Kreibich H., Kron A., Thieken A. H., Ihringer J., Oberle P., Merz B. and Nestmann F. (2006). Flood-risk mapping: contributions towards an enhanced assessment of extreme events and associated risks. Natural Hazards and Earth System Sciences, 6, 485-503.

38. Thieken A. H., Olschewski A., Kreibich H., Kobsch S. and Merz, B. (2008). Development and 
evaluation of FLEMOps - a new Flood Loss Estimation MOdel for the private sector. In: Proverbs D., Brebbia C. A. and Penning-Rowsell E. (eds.). Flood Recovery, Innovation and Response, 315-324.

39. Thieken A. H., Kreibich H., Müller M. and Merz B. (2007). Coping with floods: preparedness, response and recovery of flood-affected residents in Germany in 2002. Hydrological Sciences Journal 52(5), 1016-1037.

40. Kuhlicke C., Begg C., Beyer M., Callsen I., Kunath A. and Löster N. (2014). Hochwasservorsorge und Schutzgerechtigkeit: Erste Ergebnisse einer Haushaltsbefragung zur Hochwassersituation in Sachsen. UFZ Discussion Papers, 15/2014, 39 p.

41. Kienzler S., Pech I., Kreibich H., Müller M. and Thieken A. H. (2015). After the extreme flood in 2002: changes in preparedness, response and recovery of flood-affected residents in Germany between 2005 and 2011. Natural Hazards and Earth System Sciences, 15(3), 505-526.

42. Hall J. W., Sayers P. B. and Dawson R. J. (2005). National-scale assessment of current and future flood risk in England and Wales. Natural Hazards, 36, 147-164.

43. Bouwer L. M., Bubeck P., and Aerts J. C. J. H. (2010). Changes in future flood risk due to climate and development in a Dutch polder area. Global Environmental Change, 20, 463-471.

44. te Linde A. H., Bubeck P., Dekkers J. E. C., de Moel H. and Aerts J. C. J. H. (2011). Future flood risk estimates along the river Rhine, Natural Hazards and Earth System Sciences, 11, 459-473.

45. Merz B., Kreibich H., Thieken A. H. and Schmidtke R. (2004). Estimation uncertainty of direct monetary flood damage to buildings. Natural Hazards and Earth System Sciences, 4(1), 153-163.

46. Meyer V. and Messner, F. (2005). National Flood Damage Evaluation Methods. A review of applied methods in England, the Netherlands, Czech Republic and Germany. UFZ Discussion Papers, 21/2005, 1-47.

47. Kreibich H. and Thieken A. H. (2008). Assessment of damage caused by high groundwater inundation. Water Resource Research, 44, W09409.

48. Seifert I., Kreibich H., Merz B. and Thieken A. H. (2010). Application and validation of FLEMOcs - a flood loss estimation model for the commercial sector. Hydrological Sciences Journal, 55(8), 1315-1324.

49. DESTATIS (Statistisches Bundesamt) (2016): Indikatoren - Preise. Available at: https://www.destatis.de/DE/ZahlenFakten/Indikator en/Konjunkturindikatoren/Preise/bpr110.html, last access 25 February 2016.

50. Müller M. (2000): Die Auswirkungen von Deichbrüchen und Heizöllagerung auf Überschwemmungsschäden bei Wohngebäuden. Versicherungswirtschaft, 2000(10), 693-696 (in German).

51. FEMA (Federal Emergency Management Agency) (2014). Homeowner's Guide to Retrofitting - Six ways to protect your home from flooding. 3rd ed. US Department of Homeland Security, Washington, DC. Available at: http://www.fema.gov/media-librarydata/1404148604102f210b5e43aba0fb393443fe7ae9cd953/FEMA_P312.pdf, last access 25 February 2016. 